\title{
SENSITIVITY OF FOUR CONTEXTUAL REMOTE SENSING BASED SURFACE ENERGY BALANCE MODELS TO SPATIAL DOMAIN
}

\author{
N. Bhattarai ${ }^{1 *}$, K. Mallick ${ }^{2}$, M. Jain ${ }^{1}$ \\ ${ }^{1}$ School for Environment and Sustainability, University of Michigan, Ann Arbor, MI 48109, USA (nbhattar@umich.edu, \\ mehajain@umich.edu) \\ ${ }^{2}$ Remote Sensing and Natural Resources Modeling, Environmental Research and Innovation Department, Luxembourg Institute of \\ Science and Technology (LIST), L4422, Belvaux, Luxembourg (kaniska.mallick@list.lu)
}

Commission III, WG III/10

KEY WORDS: Surface Energy Balance (SEB) Models, Evapotranspiration, India, Contextual remote sensing.

\begin{abstract}
:
It remains unclear how the selection of a spatial domain affects the accuracy of evapotranspiration (ET) estimates from contextual remote sensing based surface energy balance (SEB) models, particularly at large spatial scales. We thus tested the effect of spatial domain on four widely implemented contextual remote sensing based SEB models: Surface Energy Balance Algorithm for Land (SEBAL), Mapping ET with Internalized Calibration (METRIC), Simplified Surface Energy Balance Index (S-SEBI), and Triangular ET models. We applied these models on 44 near cloud-free Moderate Resolution Imaging Spectroradiometer (MODIS) thermal images across all of India from 2004 to 2006. Four spatial domains were considered: all of India, agro-ecological regions, $300 \mathrm{~km} \times 300 \mathrm{~km}$ grids, and $600 \mathrm{~km} \times 600 \mathrm{~km}$ grids and we compared hourly ET estimates from the models against observed ET data at four Bowen Ratio sites in India. Model performance varied across all models and spatial domains. ET values of neighboring pixels across spatial domains formed sharp edges along the boundaries of agro-ecological regions, $300 \mathrm{~km} \times 300 \mathrm{~km}$ grids, and 600 $\mathrm{km} \times 600 \mathrm{~km}$ grids suggesting that all ET models are highly sensitive to the selection of spatial domain. No single spatial domain was found to be optimal for all models and hence potential uncertainties associated with the selection of spatial domain should be taken into consideration when implementing these models at regional scales. The results from this study provide guidance for future regional-scale implementation of ET models and potential approaches to overcome these challenges.
\end{abstract}

\section{INTRODUCTION}

Thermal remote sensing-based surface energy balance (SEB) models are widely used to map evapotranspiration (ET) from local to regional scales (Liou and Kar, 2014; Kalma et al., 2008). These models use remotely sensed land surface temperature (LST) or radiometric surface temperature $\left(T_{R}\right)$ to derive ET (or latent heat flux, $L E$ ) either as a residual of the SEB or through partitioning of the net available energy $(\phi)$ (i.e., net radiation, $R_{\mathrm{N}}$ - soil heat flux, $G$ ) into sensible heat flux $(H)$ and latent heat flux $(L E)$. In the context of India, where in-situ weather and ET validation datasets are not readily available, only limited attempts have been made to generate remotely sensed ET maps at regional scales (Mallick et al., 2009; Eswar et al., 2013). Instead, the focus has been on the application of contextual remote sensing based SEB models at relatively small spatial scales (Eswar et al., 2017a; Eswar et al., 2017b). The contextual remote sensing based SEB models are those that use thermal, vegetation, or both thermal and vegetation information from neighboring pixels within an image (Chirouze et al., 2014) to estimate dry and wet extremes and calculate ET for all pixels within these two extremes. Examples include relatively simple models, such as S-SEBI (Roerink et al., 2000) and the Triangular method (Jiang and Islam, 1999) to moderately complex but widely used models, such as SEBAL (Bastiaanssen et al., 1998) and METRIC (Allen et al., 2007). The first two SEB models do not require detailed vegetation (crop height) and weather (e.g. wind speed) information and are widely used in India (Kundu et al., 2018; Danodia et al., 2017; Eswar et al., 2017a). Only limited studies (Bala et al., 2016) have applied SEBAL or METRIC models in India, potentially due to the complexities associated with the manual selection of anchor pixels ("hot" and "cold" pixels) in these models and the need for hourly scale weather data. Recently developed automated tools for anchor pixel selection in SEBAL and METRIC models (Bhattarai et al., 2017a; Allen et al., 2013) and the availability of global scale weather forcing data (Rodell et al., 2004; Gelaro et al., 2017) have provided the means for wide-spread implementation of these models at large scales.

Previous studies (Tang et al., 2013; Long et al., 2011) have suggested that the contextual remote sensing based SEB models are sensitive to the selection of spatial domain. This is because the selection of spatial domain influences which anchor pixels are selected; "hot" and "cold" pixels within a small region (e.g., district) will be different than those selected for a larger region (e.g., state, agro-ecological zone). For example, the SEBAL model produces significantly different ET maps with a different set of anchor pixels when implemented at two different spatial domains (Tang et al., 2013). Similarly, different LST-albedo relationships (used for S-SEBI) or LST-NDVI relationships (used for the Triangular model) may result from the selection of different spatial domains, and these differences would likely affect final ET estimates. However, previous studies that have applied contextual remote sensing based SEB models in India have given little attention to the potential uncertainties associated with the selection of spatial domain. This is partly because there is no physical basis for the selection of a proper

* nbhattar@umich.edu 
spatial domain to implement these models. In this study, we explore the potential uncertainties associated with the application of four contextual remote sensing based SEB models in India using four different spatial domains for analysis.

\section{STUDY AREA AND DATA}

\subsection{STUDY AREA}

We focus on India because of the significance of agriculture and crop water management to the country. In addition, SEB models have not been evaluated in India to the extent that they have been evaluated in other parts of the world (Bastiaanssen et al., 2005; Bhattarai et al., 2016). Figure 1 shows the four sites for which we have on-the-ground validation data overlaid on the four different spatial domains used in this study: all of India, agro-ecological regions of India, $300 \mathrm{~km} \times 300 \mathrm{~km}$ grids, and $600 \mathrm{~km} \times 600 \mathrm{~km}$ grids.

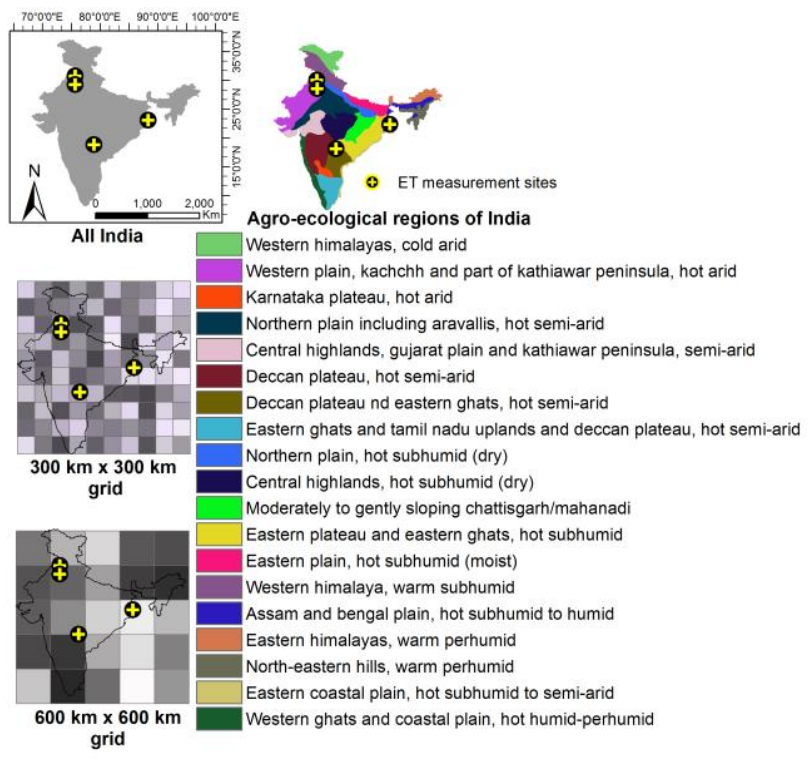

Figure 1. Four spatial domains considered for the implementation of METRIC, SEBAL, S-SEBI, and Triangular ET models in India. The agro-ecological region map was prepared by the National Bureau of Soil Survey \& Land Use Planning, India

\subsection{DATA}

As inputs into the models, we used daytime LST and emissivity products $(1 \mathrm{~km})$ from Terra MODIS (MOD11A1) (Wan et al., 2015) and surface reflectance MODIS (MOD09GA) (Vermote, 2015). Meteorological forcing data were obtained from NASA Merra-2 reanalysis products (Gelaro et al., 2017). Daytime (near Terra MODIS overpass time) Bowen ratio energy balance (BREB) ET data (Mallick et al., 2009) for 44 near cloud-free days (February 2004 to May 2006) from four sites were used to evaluate SEB models.

\section{METHODS}

\subsection{SEB models}

In this study, we considered four widely used contextual remote sensing based SEB models: SEBAL, METRIC, S-SEBI, and the
Triangular ET model. To calculate ET, all models use some form of "hot" and "cold" pixel or "dry" and "wet" edge selection based on information from all pixels within an image. For example, SEBAL and METRIC models use manually or automatically selected hot and cold pixels to iteratively solve equations for $H$ and estimate ET as a residual of the SEB. The S-SEBI model uses the LST-albedo trapezoid space to directly derive evaporative fraction $(L E / \phi)$ and ET from hypothetical hot and cold edges. The Triangular ET model uses a modified form of Priestley and Taylor's (PT) equation (Priestley and Taylor, 1972) and the LST-NDVI triangular space (Jiang and Islam, 1999) to derive ET. For more detailed descriptions of these three models, readers are referred to model development (Allen et al., 2007; Bastiaanssen et al., 1998; Roerink et al., 2000; Jiang and Islam, 1999) and application papers (Bhattarai et al., 2016; Bhattarai et al., 2017b; Singh and Senay, 2015; Batra et al., 2006).

\subsection{SEB model implementation}

All 19 tiles of MODIS data covering India were mosaicked and SEB models were implemented at four different spatial domains (Figure 1): 1) all India, 2) agro-ecological regions, 3) $300 \mathrm{~km} \times$ $300 \mathrm{~km}$ grids, and 4) $600 \mathrm{~km} \times 600 \mathrm{~km}$ grids. For 2-4, models were implemented on each subset (ecoregion or grid) independently by considering pixels only within that subset. Meteorological forcing required for the SEB models were provided by NASA Merra-2 reanalysis data (Gelaro et al., 2017). Anchor pixel selection in the SEBAL and METRIC models were adapted from Bhattarai et al. (2017a). All models were implemented in an automated way to reduce biases associated with user subjectivity.

\subsection{Sensitivity testing and model evaluation}

Near image time ET fluxes (units in $\mathrm{W} \mathrm{m}^{-2}$ ) from the four Bowen Ratio sites were used to evaluate four SEB models. Common model evaluation metrics such as root mean squared error (RMSE), coefficient of determination $\left(R^{2}\right)$, percent bias error (PBias), and mean absolute error (MAE) were used in model evaluation. ET maps from the four SEB models under different spatial domains were visually inspected to detect any edge effects (i.e. sharp changes in ET values across the boundary of the agro-ecological regions, $300 \times 300 \mathrm{~km}^{2}$ grids, and $600 \times 600 \mathrm{~km}^{2}$ grids). We show ET maps for March 12, 2005 (2005-071) as a representative image to visually inspect the spatial distribution of ET produced from the SEB models using four different spatial domains. The sensitivity of models to which spatial domain is used is evaluated both using model evaluation metrics and visual inspection of neighboring ET values across spatial domains.

\section{RESULTS AND DISCUSSION}

\subsection{Performance of ET models under four different spatial domains}

Model evaluation statistics varied across all models and across all spatial domains (Figure 2). For example, the performance of SEBAL was relatively good when the model was implemented at the all India scale, while METRIC yielded relatively poor results under the same spatial domain. The Triangular and SSEBI models performed better when the models were implemented at smaller scales (i.e. agro-ecological region and $300 \mathrm{~km} \times 300 \mathrm{~km}$ grid). Notably, $R^{2}$ values from these models were relatively low at the all India scale (0.14-0.19). However, 
RMSE, MAE, and PBias from the S-SEBI model implemented at the all India scale were relatively low $\left(94 \mathrm{~W} \mathrm{~m}^{-2}\right)$ compared to those when the model was implemented at $300 \mathrm{~km} \times 300 \mathrm{~km}$ and $600 \mathrm{~km} \times 600 \mathrm{~km}$ grids $\left(102-108 \mathrm{~W} \mathrm{~m}^{-2}\right)$. While SEBAL's performance was better than other models in most cases, its performance varied widely with $R^{2}$ ranging from 0.27 to 0.57 and RMSE ranging from 69 to $89 \mathrm{~W} \mathrm{~m}^{-2}$.

Model evaluation metrics were never simultaneously the best (i.e. high $R^{2}$ and low RMSE, MAE, and close to 0 PBias) for one SEB model under one spatial domain. For example, the $R^{2}$ value from METRIC was highest (0.434) when implemented using the $300 \mathrm{~km} \times 300 \mathrm{~km}$ spatial domain; however, the RMSE value $\left(97 \mathrm{~W} \mathrm{~m}^{-2}\right)$ was lowest when using the agro-ecological region as the spatial domain.
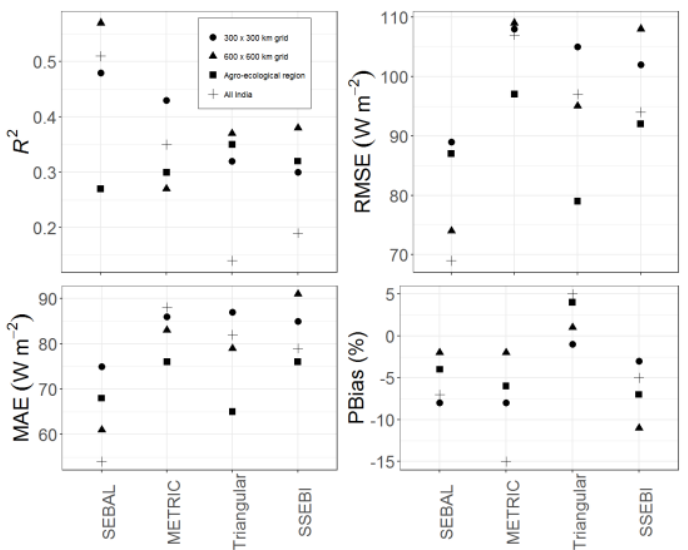

Figure 2. Model evaluation metrics of the four contextual based SEB models using the four spatial domains.

\subsection{Spatial distribution of ET under four different spatial domains}

ET maps from the four contextual SEB models showed different spatial patterns across the four spatial domains (Figure 3). In all cases, ET values from pixels within the Indo Gangetic Plains (IGP) were found to be consistent across models and were relatively high compared to ET values from other regions, which could be due to winter crop intensification and the high amounts of irrigation in this region. ET typically increases under irrigated crop conditions as a result of increased transpiration, crop growth, and crop productivity. METRIC was found to be more sensitive to the spatial domain selected compared to other models, as METRIC treats "hot" and "cold" pixels differently than other models. Specifically, METRIC considers residual $H$ values for the "cold" pixel (not 0 as in case of other models) based on reference ET (Allen et al., 1998) and, in some cases, $L E$ values for the "hot" pixel are not considered to be zero (residual precipitation). Such considerations will lead to different $H$ and $L E$ values for extreme pixels that are used to scale $H$ and $L E$ values for all other pixels within an image (Wagle et al., 2017). In some instances, there were not enough suitable pixels available to run the ET models (i.e. there were no valid "hot" and "cold" pixels in the SEBAL and METRIC models, there were not enough pixels to construct an LSTalbedo trapezoid space in S-SEBI or LST-NDVI triangular space in the Triangular ET model).

The boundary of the spatial domain was clearly visible (especially with the $300 \mathrm{~km} \times 300$ and $600 \mathrm{~km} \times 600$ grids), as ET values were significantly different at the edges of spatial domains despite being geographically close and having similar land cover type, LST values, and NDVI values. This is largely due to different LST values being selected for "hot" and "cold" pixels, and different LST-albedo and LST-NDVI trapezoid spaces being created across neighboring domains.

The spatial distribution of ET from the all India and agroecological zone spatial domains appeared to be similar across all models. However, a zoomed-in view of Eastern India (e.g., covering the borders of Bihar, West Bengal, and Jharkhand) showed that sharp edges were still persistent across agroecological zones (Figure 4). These seams were similarly apparent across the majority of neighboring agro-ecological regions across all models. Therefore it appears that all four SEB models are sensitive to the selection of the spatial domain.

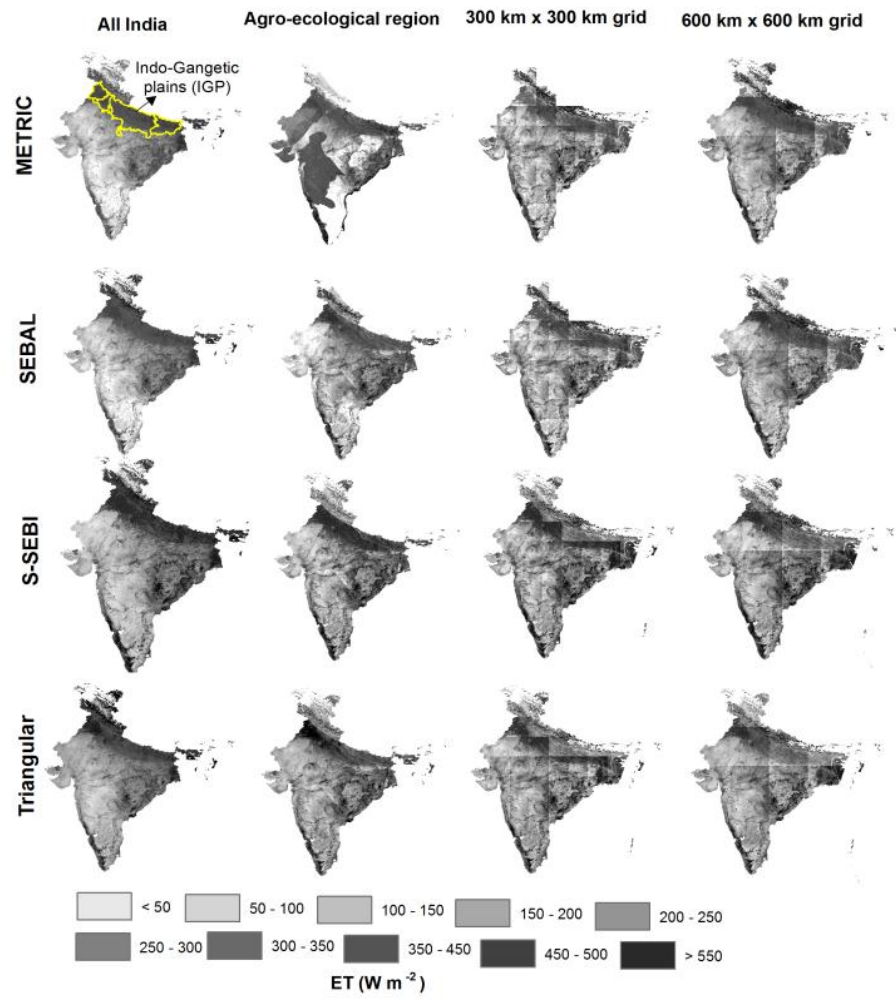

Figure 3. ET maps for March 12, 2005 from the four contextual based SEB models using the four spatial domains.

\section{CONCLUSION}

In this study, we reported potential uncertainties associated with the selection of spatial domain used to implement four widely used contextual ET models in India. Performance of the models varied widely and no single spatial domain yielded the best results for all models. The models when implemented at four different spatial domains produced distinctive ET maps, especially at the edges of the spatial domains (e.g. agroecological region, $300 \mathrm{~km} \times 300 \mathrm{~km}$ grid, and $600 \mathrm{~km} \times 600 \mathrm{~km}$ grid). Hence, all the models were found to be sensitive to spatial domain considerations. Overall, SEBAL appears to be the most accurate contextual remote sensing based ET model among the four models considered in this study. SEBAL had the highest $\mathrm{R}^{2}$ and lowest RMSE values when using the All-India, $600 \mathrm{~km} \mathrm{x}$ $600 \mathrm{~km}$ grids, and $300 \mathrm{~km} \mathrm{x} 300 \mathrm{~km}$ spatial domains. In particular, if a seamless ET map (with no edge effects) is 
desired, SEBAL at the all India scale produces the most accurate results. The Triangular ET model outperformed SEBAL when using agro-ecological region as the spatial domain. We also found that METRIC should be applied with caution at regional scales, as the model was found to be highly sensitive to which spatial domain was used for analysis. Future ET modelling studies in India using contextual remote sensing based SEB models should take these uncertainties into consideration, especially if an ET map at large spatial scales, such as all of India, is required. Future work will explore ways to reduce the impact of spatial domain selection, including developing a multi-model mean ensemble modeling framework.

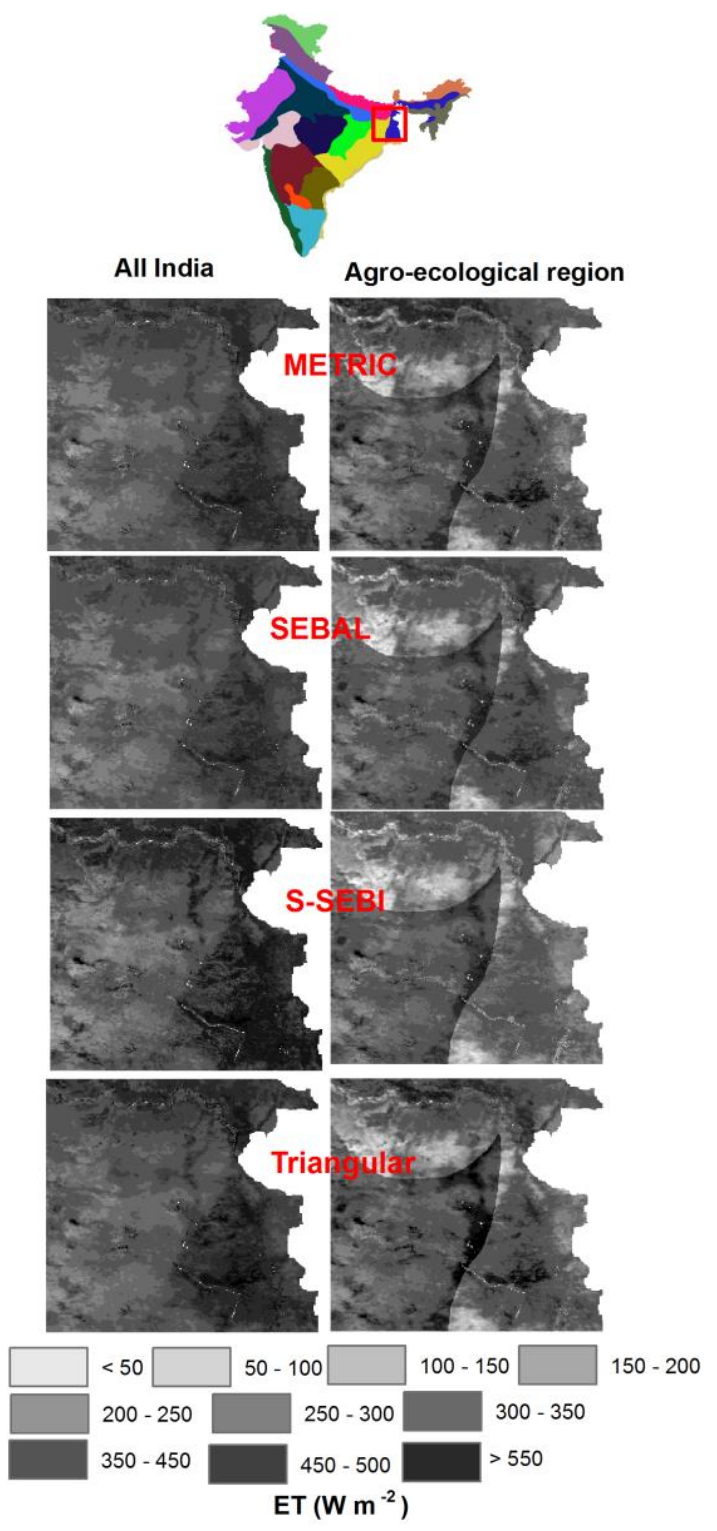

Figure 4. A zoomed-in view of ET maps for Eastern India for March 12, 2005 using all India and agro-ecological region as the spatial domains for the implementation of four contextual remote sensing based SEB models.

\section{ACKNOWLEDGEMENTS}

This study is a part of a project funded by the NASA Land Cover Land-Use Change Grant (NNX17AH97G) and the NASA new investigator program award (NNX16AI19G) awarded to MJ. KM was supported by the HiWET consortium jointly funded by the Belgian Science Policy (BELSPO)Fonds National de la Recherche (FNR)-Luxembourg under the program STEREOIII (INTER/STEREOIII/13/03/HiWET; CONTRACT NR SR/00/301).

\section{REFERENCES}

Allen, R. G., Pereira, L. S., Raes, D., and Smith, M., 1998. Crop evapotranspiration-Guidelines for computing crop water requirements-FAO Irrigation and drainage paper 56. FAO, Rome, 300(9), pp. D05109.

Allen, R. G., Tasumi, M., and Trezza, R., 2007. Satellite-based energy balance for mapping evapotranspiration with internalized calibration (METRIC) - Model. Journal of Irrigation and Drainage Engineering, 133(4), pp. 380-394.

Allen, R. G., Burnett, B., Kramber, W., Huntington, J., Kjaersgaard, J., Kilic, A., Kelly, C., and Trezza, R., 2013. Automated Calibration of the METRIC-Landsat Evapotranspiration Process. Journal of the American Water Resources Association, 49(3), pp. 563-576.

Bala, A., Rawat, K. S., Misra, A. K., and Srivastava, A., 2016. Assessment and validation of evapotranspiration using SEBAL algorithm and Lysimeter data of IARI agricultural farm, India. Geocarto International, 31(7), pp. 739-764.

Bastiaanssen, W. G. M., Menenti, M., Feddes, R. A., and Holtslag, A. A. M., 1998. A remote sensing surface energy balance algorithm for land (SEBAL): 1. Formulation. Journal of Hydrology, 212-213(1-4), pp. 198-212.

Bastiaanssen, W. G. M., Noordman, E. J. M., Pelgrum, H., Davids, G., Thoreson, B. P., and Allen, R. G., 2005. SEBAL model with remotely sensed data to improve water-resources management under actual field conditions. Journal of Irrigation and Drainage Engineering, 131(1), pp. 85-93.

Batra, N., Islam, S., Venturini, V., Bisht, G., and Jiang, L., 2006. Estimation and comparison of evapotranspiration from MODIS and AVHRR sensors for clear sky days over the Southern Great Plains. Remote sensing of Environment, 103(1), pp. $1-15$.

Bhattarai, N., Shaw, S. B., Quackenbush, L. J., Im, J., and Niraula, R., 2016. Evaluating five remote sensing based singlesource surface energy balance models for estimating daily evapotranspiration in a humid subtropical climate. International Journal of Applied Earth Observation and Geoinformation, 49(July 2016), pp. 75-86.

Bhattarai, N., Quackenbush, L. J., Im, J., and Shaw, S. B., 2017a. A new optimized algorithm for automating endmember pixel selection in the SEBAL and METRIC models. Remote sensing of Environment, 196(July 2017), pp. 178-192. 
Bhattarai, N., Wagle, P., Gowda, P. H., and Kakani, V. G., 2017b. Utility of remote sensing-based surface energy balance models to track water stress in rain-fed switchgrass under dry and wet conditions. ISPRS Journal of Photogrammetry and Remote Sensing, 133(November 2017), pp. 128-141.

Chirouze, J., Boulet, G., Jarlan, L., Fieuzal, R., Rodriguez, J. C., Ezzahar, J., Er-Raki, S., Bigeard, G., Merlin, O., GaratuzaPayan, J., Watts, C., and Chehbouni, G., 2014. Intercomparison of four remote-sensing-based energy balance methods to retrieve surface evapotranspiration and water stress of irrigated fields in semi-arid climate. Hydrology and Earth System Sciences, 18(3), pp. 1165-1188.

Danodia, A., Patel, N. R., Chol, C. W., Nikam, B. R., and Sehgal, V. K., 2017. Application of S-SEBI model for crop evapotranspiration using Landsat- 8 data over parts of North India. Geocarto International, pp. 1-18.

Eswar, R., Sekhar, M., and Bhattacharya, B. K., 2013. A simple model for spatial disaggregation of evaporative fraction: Comparative study with thermal sharpened land surface temperature data over India. Journal of Geophysical Research: Atmospheres, 118(21), pp. 12,029-012,044.

Eswar, R., Sekhar, M., and Bhattacharya, B., 2017a. Comparison of three remote sensing based models for the estimation of latent heat flux over India. Hydrological Sciences Journal, 62(16), pp. 2705-2719.

Eswar, R., Sekhar, M., Bhattacharya, B., and Bandyopadhyay, S., 2017b. Spatial Disaggregation of Latent Heat Flux Using Contextual Models over India. Remote Sensing, 9(9), pp. 949.

Gelaro, R., McCarty, W., Suárez, M. J., Todling, R., Molod, A., Takacs, L., Randles, C. A., Darmenov, A., Bosilovich, M. G., Reichle, R., Wargan, K., Coy, L., Cullather, R., Draper, C., Akella, S., Buchard, V., Conaty, A., Silva, A. M. d., Gu, W., Kim, G.-K., Koster, R., Lucchesi, R., Merkova, D., Nielsen, J. E., Partyka, G., Pawson, S., Putman, W., Rienecker, M., Schubert, S. D., Sienkiewicz, M., and Zhao, B., 2017. The Modern-Era Retrospective Analysis for Research and Applications, Version 2 (MERRA-2). Journal of Climate, 30(14), pp. 5419-5454.

Jiang, L., and Islam, S., 1999. A methodology for estimation of surface evapotranspiration over large areas using remote sensing observations. Geophysical Research Letters, 26(17), pp. 2773-2776.

Kalma, J. D., McVicar, T. R., and McCabe, M. F., 2008. Estimating land surface evaporation: A review of methods using remotely sensed surface temperature data. Surveys in Geophysics, 29(4-5), pp. 421-469.

Kundu, S., Mondal, A., Khare, D., Hain, C., and Lakshmi, V., 2018. Projecting Climate and Land Use Change Impacts on Actual Evapotranspiration for the Narmada River Basin in Central India in the Future. Remote Sensing, 10(4), pp. 578.

Liou, Y.-A., and Kar, S. K., 2014. Evapotranspiration estimation with remote sensing and various surface energy balance algorithms-A review. Energies, 7(5), pp. 2821-2849.
Long, D., Singh, V. P., and Li, Z. L., 2011. How sensitive is SEBAL to changes in input variables, domain size and satellite sensor? Journal of Geophysical Research: Atmospheres, 116(21), pp. D21107.

Mallick, K., Bhattacharya, B. K., Rao, V. U. M., Reddy, D. R., Banerjee, S., Venkatesh, H., Pandey, V., Kar, G., Mukherjee, J., Vyas, S. P., Gadgil, A. S., and Patel, N. K., 2009. Latent heat flux estimation in clear sky days over Indian agroecosystems using noontime satellite remote sensing data. Agricultural and Forest Meteorology, 149(10), pp. 1646-1665.

Priestley, C., and Taylor, R., 1972. On the assessment of surface heat flux and evaporation using large-scale parameters. Monthly weather review, 100(2), pp. 81-92.

Rodell, M., Houser, P. R., Jambor, U., Gottschalck, J., Mitchell, K., Meng, C.-J., Arsenault, K., Cosgrove, B., Radakovich, J., Bosilovich, M., Entin, J. K., Walker, J. P., Lohmann, D., and Toll, D., 2004. The Global Land Data Assimilation System. Bulletin of the American Meteorological Society, 85(3), pp. 381-394.

Roerink, G. J., Su, Z., and Menenti, M., 2000. S-SEBI: A simple remote sensing algorithm to estimate the surface energy balance. Physics and Chemistry of the Earth, Part B: Hydrology, Oceans and Atmosphere, 25(2), pp. 147-157.

Singh, R. K., and Senay, G. B., 2015. Comparison of four different energy balance models for estimating evapotranspiration in the Midwestern United States. Water, $8(1)$, pp. 9.

Tang, R., Li, Z.-L., Chen, K.-S., Jia, Y., Li, C., and Sun, X., 2013. Spatial-scale effect on the SEBAL model for evapotranspiration estimation using remote sensing data. Agricultural and Forest Meteorology, 174(15 June 2013), pp. $28-42$.

Vermote, E.: MOD09A1MODIS/Terra Surface Reflectance 8Day L3 Global 500m SIN Grid V006, 2015.

Wagle, P., Bhattarai, N., Gowda, P. H., and Kakani, V. G., 2017. Performance of five surface energy balance models for estimating daily evapotranspiration in high biomass sorghum. ISPRS Journal of Photogrammetry and Remote Sensing, 128(pp. 192-203.

Wan, Z., Hook, S., and Hulley, G.: MOD11A2 MODIS/Terra Land Surface Temperature/Emissivity 8-Day L3 Global $1 \mathrm{~km}$ SIN Grid V006, 2015. 